\title{
Continuous Postoperative Respiratory Monitoring with Calibrated Respiratory Effort Belts: Pilot Study
}

\author{
Tiina M Seppänen ${ }^{1,2}$, Olli-Pekka Alho ${ }^{2,3,4}$, Merja Vakkala ${ }^{2,5}$, Seppo Alahuhta ${ }^{2.5}$, and \\ Tapio Seppänen ${ }^{1,2}$ \\ ${ }^{1}$ Physiological Signal Analysis Team, University of Oulu, Oulu, Finland \\ ${ }^{2}$ Medical Research Center Oulu, Oulu University Hospital and University of Oulu, Oulu, Fin- \\ land \\ \{tiina.seppanen, tapio.seppanen\}@oulu.fi \\ ${ }^{3}$ Department of Otorhinolaryngology, Oulu University Hospital, Oulu, Finland \\ ${ }^{4}$ PEDEGO Research Unit, University of Oulu, Oulu, Finland \\ ollii-pekka.alho@oulu.fi \\ ${ }^{5}$ Department of Anesthesiology, Oulu University Hospital, Oulu, Finland \\ merja.vakkala@ppshp.fi, seppo.alahuhta@oulu.fi
}

\begin{abstract}
Postoperative respiratory complications are common in patients after surgery. Respiratory depression and subsequent adverse outcomes can arise from pain, residual effects of drugs given during anaesthesia and administration of opioids for pain management. There is an urgent need for a continuous, realtime and non-invasive respiratory monitoring of spontaneously breathing postoperative patients. For this purpose, we used rib cage and abdominal respiratory effort belts for the respiratory monitoring pre- and postoperatively, with a new calibration method that enables accurate estimates of the respiratory airflow waveforms even when breathing style changes. Five patients were measured with respiratory effort belts and mask spirometer. Preoperative measurements were done in the operating room, whereas postoperative measurements were done in the recovery room. We compared five calibration models with pre- and postoperative training data. The postoperative calibration approach with two respiratory effort belts produced the most accurate respiratory airflow waveforms and tidal volume, minute volume and respiratory rate estimates. Average results for the best model were: coefficient of determination $\mathrm{R}^{2}$ was 0.91 , tidal volume error $5.8 \%$, minute volume error $8.5 \%$ and BPM (Breaths per Minute) error 0.21 . The method performed well even in the following challenging respiratory cases: low airflows, thoracoabdominal asynchrony and hypopneic events. It was shown that a single belt measurement can be sufficient in some cases. The proposed method is able to produce estimates of postoperative respiratory airflow waveforms to enable accurate, continuous, real-time and noninvasive respiratory monitoring postoperatively. It provides also potential to optimize postoperative pain management and enables timely interventions.
\end{abstract}

Keywords: Airflow waveform · Calibration · Regression · Respiratory airflow · Respiratory rate $\cdot$ Respiratory volume 


\section{$1 \quad$ Introduction}

Respiratory complications are common in surgical patients after the general anaesthesia. Postoperative respiratory depression and subsequent adverse outcomes can arise from pain, residual effects of drugs given during anaesthesia and administration of opioids for pain management [1]. Respiratory depression often occurs in association with postoperative opioid analgesia [2,3,4]. The risk of respiratory depression increases with age [1], morbid obesity [5] and pre-existing sleep apnea syndrome [2].

Inadequate respiration can result in respiratory complications, morbidity, mortality, longer recovery room times and excessive costs. Abnormal respiratory rate has been shown to be a common clinical feature in patients before a major clinical event such as cardiac arrest, onset of sepsis, and in patients experiencing pain, shock, asthma attacks and respiratory infection [6,7]. Adequate respiration monitoring postoperatively is important, so that respiratory depression can be identified as early as possible $[8,9]$. This way, we would minimize respiratory complications, facilitate timely interventions, reduce health care costs, and improve patient safety and satisfaction.

During general anaesthesia, mechanical ventilation with intubation or supraglottic device is used, and consequently, monitoring of respiration and gas exchange can be done accurately. During postoperative care, respiratory status can be assessed, for example, with capnometry, pulse oximetry, oxygen saturation $\left(\mathrm{SpO}_{2}\right)$ measurements, blood gas measurements, subjective clinical assessment and intermittent, manual measurements of respiratory rate $[5,9]$. The problems with current methods are that they have poor accuracy, precision, low patient tolerance and they are liable to false alarms $[10,11]$. Additionally, they are slow and especially subjective methods are unreliable and give inconsistent results [12]. Current methods do not provide information about respiratory airflow waveform variability and disorders, either. There is thus a need for a continuous, real time and non-invasive respiratory monitoring of spontaneously breathing postoperative patients.

A couple of studies have been recently published on monitoring postoperative respiration continuously and non-invasively. Drummond et al. [13] have studied respiratory rate and breathing patterns of postoperative subjects using encapsulated tri-axial accelometer taped to a subject's body. They found that abnormal breathing patterns are extremely common. Voscopoulos et al. $[14,15,16]$ have studied minute ventilation, tidal volume and respiratory rate of postoperative subjects using impedancebased electrodes placed to a subject's body. In addition to these, Masa et al. [17] showed that respiratory effort-related arousals in sleep apnea patients could be identified satisfactorily by assessing the morphology of the thoracoabdominal bands output signal.

Recently, we published a novel calibration method to produce accurate estimates of respiratory airflow signals from respiratory effort belt signals [18]. The method is an extension to the multiple linear regression method with two predictor variables: rib cage and abdominal respiratory effort belt signals Here, the method is used in order to produce estimates of postoperative respiratory airflow waveforms to enable accurate, continuous, non-invasive respiratory monitoring postoperatively. Pre- and postoperative measurement data of different patients are used to demonstrate the performance 
of the method. Additionally, we assess the calibration method by using only one predictor variable (rib cage respiratory effort belt or abdominal respiratory effort belt) at the time. The results are assessed between the belts and also compared to the results from two belts.

\section{Materials and Methods}

\subsection{Materials}

The study protocol was approved by the Regional Ethics Committee of the Northern Ostrobothnia Hospital District. Five patients who had lumbar back surgery and were expected to need opioid analgesia postoperatively were recruited to the study after informed consent. Exclusion criteria were the planned surgical wound being in the area where respiratory effort belts were placed and BMI (Body Mass Index) over 40. The characteristics of the volunteers are given in Table 1 .

Table 1. Characteristics of volunteers (COPD $=$ Chronic Obstructive Pulmonary Disease)

\begin{tabular}{l|l|l|l|l}
\hline Patient & Gender & Age [years] & BMI $\left[\mathrm{kg} / \mathrm{m}^{2}\right]$ & Disease \\
\hline 1 & M & 68 & 22 & None \\
\hline 2 & M & 41 & 30 & None \\
\hline 3 & F & 77 & 22 & None \\
\hline 4 & M & 64 & 28 & COPD \\
\hline 5 & M & 67 & 27 & Sleep apnea \\
\hline
\end{tabular}

Respiratory effort belt signals were recorded with the polygraphic recorder (Embletta Gold, Denver, Colorado, USA). The recorder had inductive respiratory effort belts for rib cage and abdomen. The belt signals stored by the recorder were in arbitrary units and therefore they had to be calibrated to get respiratory airflow estimates in proper units. For calibrating the respiratory effort belt signals, simultaneous respiratory airflow signal was recorded with a spirometer (Medikro Pro M915, Medikro Oy, Kuopio, Finland). Before each measurement session, the spirometer was calibrated using a $3000 \mathrm{ml}$ calibration syringe (Medikro M9474, Medikro Oy, Kuopio, Finland). A mask covering the mouth and nose (Cortex Personal-Use-Mask, Leipzig, Germany) was attached to the mouthpiece of the spirometer. The spirometer was able to record at most $1 \mathrm{~min}$ long signals. The sampling rate of respiratory effort belts and spirometer was $50 \mathrm{~Hz}$ and $100 \mathrm{~Hz}$, respectively. The spirometer signals were decimated to $50 \mathrm{~Hz}$ for further processing.

\subsection{Measurement Protocol}

The measurements for each patient were done in two sessions: 1) a short measurement session (5 min) preoperatively; and 2) a longer measurement session ( $3 \mathrm{~h}$ ) postoperatively. 
The first measurements were done in the operating room just before the operation prior to patients had received any sedative premedication. The rib cage respiratory effort belt was placed on the xyphoid process and the abdominal belt just above the umbilicus. The mask of the spirometer was put on the patient's face and its airtightness was secured. The signals were recorded until two successful recordings of the 1 min were obtained. After that, the places of respiratory effort belts were marked with drawing ink on the skin, so that it was possible to place the belts to the same places postoperatively. The mask and respiratory effort belts were removed.

Patients were operated in general anaesthesia. As soon as possible, measurements were continued postoperatively in the recovery room. The rib cage respiratory effort belt and the abdominal respiratory effort belt were placed to the preoperatively marked places. They recorded the signals during the whole 3 hour measurement period. Every $10 \mathrm{~min}$, the mask with the spirometer was put on the subject's face, its airtightness was secured and 1 min measurement with the spirometer was recorded. Participation to the study did not affect the routine management of the patients.

\subsection{Calculation of Respiratory Airflow Estimates}

In this study, we applied our recently published respiratory effort belt calibration method [18]. The method was therein tested against various breathing style changes and body position changes, and compared with the state-of-the-art methods. It was found out that our method outperformed the other methods showing highest robustness to the breathing style changes and body position changes.

Our method is an extension to the conventional multiple linear regression method so that 1) it uses number $\mathrm{N}$ of consecutive input signal samples and linear filtering for estimation of each output signal sample and 2) it is based on polynomial regression to model different transfer functions between the input and output. The method is based on optimally trained FIR (Finite Impulse Response) filter bank constructed as a MISO (Multiple-Input Single-Output) system between the respiratory effort belt signals and the spirometer signal, see Fig. 1. The following polynomial transfer functions were tested: linear terms only (M1), linear terms and cross-product term (M2), and linear terms with second order terms (M3). Additionally, we tested a linear model with only one respiratory effort belt at the time: abdominal respiratory effort belt (M4) and rib cage respiratory effort belt (M5).

Equation 1 shows the realization of the filter bank for model M2. Similar realizations can be derived also for models M1, M3, M4 and M5.

$$
y[k]=\boldsymbol{a}_{1}^{T} \boldsymbol{x}_{1}[k]+\boldsymbol{a}_{2}^{T} \boldsymbol{x}_{2}[k]+\boldsymbol{a}_{3}^{T}\left(\boldsymbol{x}_{1}[k] \boldsymbol{x}_{2}[k]\right)+\varepsilon[k],
$$

where $\boldsymbol{a}_{1}^{T}, \boldsymbol{a}_{2}^{T}$ and $\boldsymbol{a}_{3}^{T}$ denote the $\mathrm{N}$ tap coefficients of filters FIR1, FIR2 and FIR3, respectively:

$$
\boldsymbol{a}_{i}^{T}=\left[a_{i}[1], a_{i}[2], \ldots, a_{i}[N]\right]
$$

where $\mathrm{i}=1,2$, 3. Superscript $\mathrm{T}$ denotes matrix transpose. Parameter $y$ (response variable) denotes respiratory airflow from spirometer and $\varepsilon$ is zero-mean Gaussian error. 


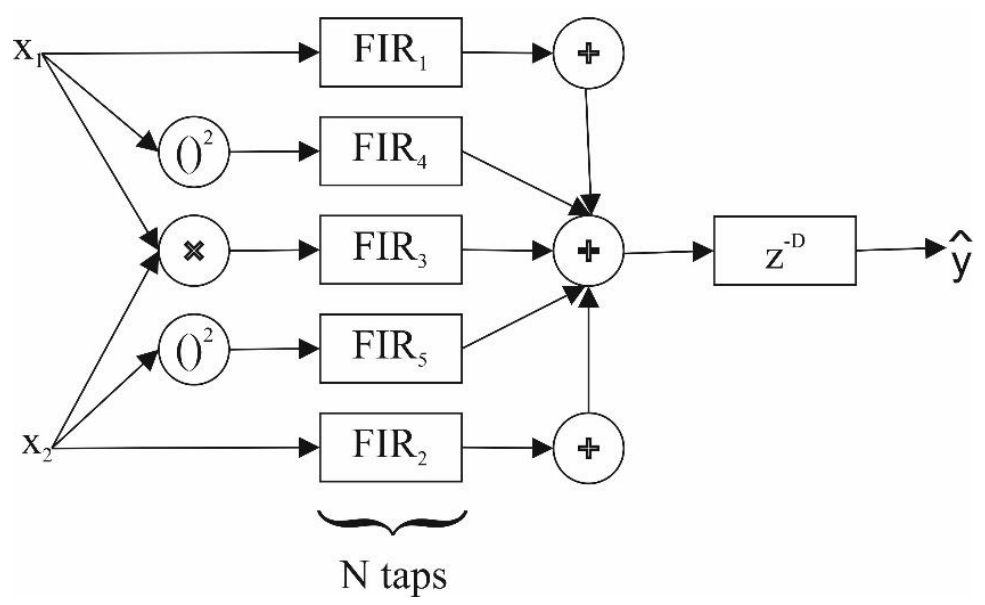

Fig. 1. Calibration method of respiratory effort belt signals used in this study

Vectors $\boldsymbol{x}_{1}$ and $\boldsymbol{x}_{2}$ (predictor variables) include $\mathrm{N}$ consecutive signal samples from the rib cage respiratory effort belt signal and abdominal respiratory effort belt signal, respectively:

$$
\boldsymbol{x}_{j}[k]=\left[x_{j}[k], x_{j}[k-1], \ldots, x_{j}[k-N+1]\right]^{T},
$$

where $\mathrm{j}=1,2$ and $\mathrm{k}=\mathrm{N}, \ldots, \mathrm{n}$. Variable $\mathrm{n}$ is the number of observations used in the calibration. $\boldsymbol{X}$ is an $(\mathrm{n}-\mathrm{N}+1) \times(3 \times \mathrm{N})$ matrix formed from the vectors $\boldsymbol{x}_{1}$ and $\boldsymbol{x}_{2}$ :

$$
\widehat{\boldsymbol{a}}=\left(\boldsymbol{X}^{T} \boldsymbol{X}\right)^{-1} \boldsymbol{X}^{T} \boldsymbol{y} .
$$

The length of the vector $\widehat{a}$ is $3 \times$ N. Finally, the respiratory airflow signal estimated from the rib cage and abdominal respiratory effort belt signals through the FIR filter bank is

$$
\widehat{\boldsymbol{y}}=\boldsymbol{X} \widehat{\boldsymbol{a}} .
$$

In Fig. 1 , there is the delay element $\mathrm{z}^{-\mathrm{D}}$ included at the output. There is always a small delay between the spirometer signal and respiratory effort belt signals due to the physiological reasons and internal delays of measuring devices. Thus, the signals have to be time-synchronized by searching for a proper value for $\mathrm{D}$ [18].

Based on our previous study [18], we used $0.15 \mathrm{sec}$ and $0.30 \mathrm{sec}$ time windows of FIR filters in this study. With the used sampling frequency of $50 \mathrm{~Hz}$, the number of tap coefficients $(\mathrm{N})$ was 8 and 16 , respectively.

We made two different test setups: 1) the data of the second preoperative measurement minute were used to train the estimation model and the data of all the postoperative measurement minutes were used to test the estimation model (PRE setup); and 2) the data of the first postoperative measurement minute were used to train the estimation model and data of the rest of postoperative measurement minutes were used to test the estimation model (POST setup). 


\subsection{Statistics}

The similarity of spirometer signals and estimated respiratory airflow signals were assessed by computing $\mathrm{R}^{2}$ (coefficient of determination) and RMSE (Root Mean Square Error) values. $\mathrm{R}^{2}$ is the coefficient of determination between the spirometer signal and the estimated airflow. The coefficient of determination is calculated from [19]

$$
R^{2}=1-\frac{S S_{r e s}}{S S_{\text {tot }}},
$$

where $\mathrm{SS}_{\text {res }}$ is the sum of squares of residuals between the spirometer signal and estimated airflow, and $\mathrm{SS}_{\text {tot }}$ is the total sum of squares calculated from the spirometer signal. RMSE is a measure of the difference between the spirometer signal and the estimated airflow. Relative RMSE [\%] is the proportion of RMSE from RMS (Root Mean Square) of the spirometer signal. Tidal volumes, minute volumes and BPM (Breaths per Minute, respiratory rate) were calculated from the spirometer signals and estimated respiratory airflow signals. Relative errors were calculated.

\section{$3 \quad$ Results and Discussion}

Signals were recorded according to the protocol described in Section 2.2. A total of 93 simultaneous measurement minutes with spirometer and respiratory effort belts were collected. Five of these had to be discarded due to a malfunction of the spirometer, one of them due to a malfunction of the polygraphic recorder. In addition to that, five postoperative measurement minutes of patient 5 had to be discarded, because of serious difficulties to wake up and stay awake in the recovery room. During the measurements, patients received opioid analgesia as many times as they needed: 3, 2, 1, 6 and 4 times for patients $1-5$, respectively.

The following problems related to PRE setup were observed during the measurements. Firstly, there may be a need to tighten or loosen the respiratory effort belts after the operation, because fluids can accumulate in the body or can leave from the body during the operation. This leads to a situation where the estimation model trained with a preoperative data is not valid anymore. Secondly, if there are complications during the operation, the estimation model trained with a preoperative data can be erroneous for the postoperative data. With the POST setup, no problems were observed.

\subsection{Accuracy of Airflow Estimates Using Two Respiratory Effort Belts}

Results for the models using two respiratory effort belts, namely M1, M2 and M3, are presented first. After that, the results for the models (M4 and M5) using only one respiratory effort belt are presented. At the end of this section, the results of those cases are compared. The selection of the best model and FIR filter length ( $\mathrm{N}$ value) depended on whether waveform accuracy $\left(\mathrm{R}^{2}\right.$, relative RMSE), tidal volume $\left(\mathrm{V}_{\mathrm{T}}\right)$ error, minute volume $\left(\mathrm{V}_{\text {minute }}\right)$ error or BPM error values were studied. 
Table 2 summarizes the best results when PRE setup was used for training and testing estimation models M1, M2 and M3. As seen from Table 2, model M1 produced the best results in all cases. $\mathrm{N}$ value 8 produced the best waveform accuracy and the lowest volume errors. $\mathrm{N}$ value 16 produced the lowest BPM error, but the respective result with $\mathrm{N}$ value 8 was almost the same namely $0.34 \pm 0.71$.

Table 2. Best results (average value \pm SD) with the best models when PRE setup was used for training and testing estimation models M1, M2 and M3.

\begin{tabular}{l|l|l|l|l|l}
\hline Best model & $\mathrm{M} 1$ & $\mathrm{M} 1$ & $\mathrm{M} 1$ & $\mathrm{M} 1$ & $\mathrm{M} 1$ \\
\hline FIR size & $\mathrm{N}=8$ & $\mathrm{~N}=8$ & $\mathrm{~N}=8$ & $\mathrm{~N}=8$ & $\mathrm{~N}=16$ \\
\hline Patient & $\mathrm{R}^{2}$ & $\begin{array}{l}\text { Relative } \\
\text { RMSE }[\%]\end{array}$ & $\begin{array}{l}\text { Abs }\left(\mathrm{V}_{\mathrm{T}}\right. \\
\text { error })[\%]\end{array}$ & $\begin{array}{l}\text { Abs }\left(\mathrm{V}_{\text {minute }}\right. \\
\text { error })[\%]\end{array}$ & $\mathrm{BPM}$ error \\
\hline 1 & $0.88 \pm 0.05$ & $33.4 \pm 6.5$ & $12.8 \pm 10.7$ & $12.8 \pm 10.7$ & $0.03 \pm 0.07$ \\
\hline 2 & $0.87 \pm 0.06$ & $35.2 \pm 7.0$ & $26.7 \pm 7.7$ & $25.1 \pm 8.2$ & $0.01 \pm 0.01$ \\
\hline 3 & $0.94 \pm 0.02$ & $24.4 \pm 4.5$ & $10.9 \pm 2.9$ & $14.2 \pm 5.0$ & $0.09 \pm 0.30$ \\
\hline 4 & $0.87 \pm 0.06$ & $35.8 \pm 7.9$ & $15.9 \pm 6.0$ & $21.7 \pm 8.6$ & $0.09 \pm 1.14$ \\
\hline 5 & $0.40 \pm 0.18$ & $76.7 \pm 12.2$ & $71.0 \pm 13.7$ & $76.4 \pm 17.7$ & $0.64 \pm 0.90$ \\
\hline Average & $0.81 \pm 0.20$ & $39.2 \pm 18.2$ & $24.9 \pm 22.2$ & $27.3 \pm 23.7$ & $0.32 \pm 0.73$ \\
\hline
\end{tabular}

Table 3 summarizes the best results when the POST setup was used for training and testing estimation models M1, M2 and M3. In this case, it is seen that model M2 produced the best results in all cases. $\mathrm{N}$ value 8 produced the best waveform accuracy and the lowest BPM error, whereas $\mathrm{N}$ value 16 produced the lowest volume errors. As an important difference to the preceding results in Table 2, more accurate waveforms were received since $\mathrm{R}^{2}$ values were higher, relative RMSE lower and BPM error values lower. Also, the volume error values decreased to the fractions.

Table 3. Best results (average value $\pm \mathrm{SD}$ ) with the best models when POST setup was used for training and testing estimation models M1, M2 and M3.

\begin{tabular}{l|l|l|l|l|l}
\hline Best model & $\mathrm{M} 2$ & $\mathrm{M} 2$ & $\mathrm{M} 2$ & $\mathrm{M} 2$ & $\mathrm{M} 2$ \\
\hline FIR size & $\mathrm{N}=8$ & $\mathrm{~N}=8$ & $\mathrm{~N}=16$ & $\mathrm{~N}=16$ & $\mathrm{~N}=8$ \\
\hline Patient & $\mathrm{R}^{2}$ & $\begin{array}{l}\text { Relative } \\
\text { RMSE [\%] }\end{array}$ & $\begin{array}{l}\text { Abs }\left(\mathrm{V}_{\mathrm{T}}\right. \\
\text { error) }[\%]\end{array}$ & $\begin{array}{l}\text { Abs }\left(\mathrm{V}_{\text {minute }}\right. \\
\text { error) }[\%]\end{array}$ & $\mathrm{BPM}$ error \\
\hline 1 & $0.90 \pm 0.04$ & $31.4 \pm 5.6$ & $11.4 \pm 7.9$ & $9.9 \pm 6.8$ & $0.01 \pm 0.01$ \\
\hline 2 & $0.95 \pm 0.01$ & $21.3 \pm 2.9$ & $5.9 \pm 4.5$ & $5.8 \pm 5.0$ & $0.01 \pm 0.01$ \\
\hline 3 & $0.94 \pm 0.04$ & $23.9 \pm 6.1$ & $5.4 \pm 4.7$ & $6.3 \pm 4.2$ & $0.10 \pm 0.30$ \\
\hline 4 & $0.88 \pm 0.09$ & $33.7 \pm 10.6$ & $8.7 \pm 6.0$ & $11.9 \pm 10.2$ & $0.83 \pm 1.13$ \\
\hline 5 & $0.91 \pm 0.02$ & $30.1 \pm 3.8$ & $10.5 \pm 9.3$ & $8.2 \pm 6.3$ & $0.01 \pm 0.00$ \\
\hline Average & $0.91 \pm 0.06$ & $28.1 \pm 8.0$ & $5.8 \pm 6.3$ & $8.5 \pm 7.1$ & $0.21 \pm 0.63$ \\
\hline
\end{tabular}

It can be seen from Table 2 and Table 3 that the POST setup produces better results than the PRE setup, and that different models yield the best results in them. However, one may wish to use only one model with good overall performance in both setups. 
The results for that are presented next. Model M3 (using two respiratory effort belt signals and including linear and $2^{\text {nd }}$ order terms) produced clearly worse results than the other models, thus, only the results of using models M1 and M2 are presented here. Table 4 presents the results when the estimation model M1 with $\mathrm{N}$ value 8 was used with PRE and POST setups.

Table 4. Results (average value $\pm \mathrm{SD})$ for estimation model M1 $(\mathrm{N}=8)$ with PRE setup (upper results) and POST setup (lower results)

\begin{tabular}{l|l|l|l|l|l}
\hline Patient & $\mathrm{R}^{2}$ & $\begin{array}{l}\text { Relative } \\
\text { RMSE [\%] }\end{array}$ & $\begin{array}{l}\text { Abs }\left(\mathrm{V}_{\mathrm{T}}\right. \\
\text { error) }[\%]\end{array}$ & $\begin{array}{l}\text { Abs }\left(\mathrm{V}_{\text {minute }}\right. \\
\text { error) [\%] }\end{array}$ & BPM error \\
\hline 1 & $0.88 \pm 0.05$ & $33.4 \pm 6.5$ & $12.8 \pm 10.7$ & $12.5 \pm 9.5$ & $0.09 \pm 0.27$ \\
\hline 2 & $0.87 \pm 0.06$ & $35.2 \pm 7.0$ & $26.7 \pm 7.7$ & $25.1 \pm 8.2$ & $0.01 \pm 0.01$ \\
\hline 3 & $0.94 \pm 0.02$ & $24.4 \pm 4.5$ & $10.9 \pm 2.9$ & $14.2 \pm 5.0$ & $0.09 \pm 0.29$ \\
\hline 4 & $0.87 \pm 0.06$ & $35.8 \pm 7.9$ & $15.9 \pm 6.0$ & $21.7 \pm 8.6$ & $1.00 \pm 1.06$ \\
\hline 5 & $0.40 \pm 0.18$ & $76.7 \pm 12.2$ & $71.0 \pm 13.7$ & $76.4 \pm 17.7$ & $0.54 \pm 0.75$ \\
\hline Average & $0.81 \pm 0.20$ & $39.2 \pm 18.2$ & $24.9 \pm 22.2$ & $27.3 \pm 23.7$ & $0.34 \pm 0.71$ \\
\hline 1 & $0.91 \pm 0.04$ & $29.2 \pm 5.6$ & $11.6 \pm 7.8$ & $8.9 \pm 7.1$ & $0.01 \pm 0.01$ \\
\hline 2 & $0.94 \pm 0.02$ & $23.7 \pm 3.5$ & $6.9 \pm 7.0$ & $5.7 \pm 5.6$ & $0.01 \pm 0.01$ \\
\hline 3 & $0.94 \pm 0.04$ & $24.0 \pm 6.2$ & $5.6 \pm 4.5$ & $6.0 \pm 3.8$ & $0.10 \pm 0.30$ \\
\hline 4 & $0.87 \pm 0.09$ & $34.3 \pm 10.5$ & $8.4 \pm 4.9$ & $11.9 \pm 8.9$ & $0.82 \pm 1.13$ \\
\hline 5 & $0.90 \pm 0.02$ & $30.8 \pm 3.9$ & $9.6 \pm 5.3$ & $10.9 \pm 4.9$ & $0.12 \pm 0.35$ \\
\hline Average & $0.91 \pm 0.06$ & $28.4 \pm 7.7$ & $8.4 \pm 6.1$ & $8.6 \pm 6.7$ & $0.23 \pm 0.64$ \\
\hline & & & & & \\
\hline
\end{tabular}

Table 5 presents the results when estimation model M2 with $\mathrm{N}$ value 8 was used with PRE and POST setups.

Table 5. Results (average value $\pm \mathrm{SD}$ ) of the calibration when estimation model M2 $(\mathrm{N}=8)$ was used with PRE setup (upper results) and POST setup (lower results).

\begin{tabular}{l|l|l|l|l|l}
\hline Patient & $\mathrm{R}^{2}$ & $\begin{array}{l}\text { Relative } \\
\text { RMSE [\%] }\end{array}$ & $\begin{array}{l}\text { Abs }\left(\mathrm{V}_{\mathrm{T}}\right. \\
\text { error) }[\%]\end{array}$ & $\begin{array}{l}\text { Abs }\left(\mathrm{V}_{\text {minute }}\right. \\
\text { error })[\%]\end{array}$ & BPM error \\
\hline 1 & $0.82 \pm 0.08$ & $41.9 \pm 9.4$ & $17.8 \pm 9.8$ & $21.3 \pm 8.3$ & $0.10 \pm 0.27$ \\
\hline 2 & $0.76 \pm 0.09$ & $48.0 \pm 8.7$ & $42.7 \pm 8.8$ & $51.7 \pm 9.6$ & $0.04 \pm 0.12$ \\
\hline 3 & $0.93 \pm 0.03$ & $26.6 \pm 5.6$ & $13.3 \pm 5.1$ & $15.3 \pm 6.4$ & $0.09 \pm 0.30$ \\
\hline 4 & $0.87 \pm 0.06$ & $34.8 \pm 7.9$ & $15.4 \pm 6.7$ & $19.6 \pm 8.6$ & $0.91 \pm 1.11$ \\
\hline 5 & $0.35 \pm 0.23$ & $79.2 \pm 14.6$ & $55.9 \pm 9.4$ & $69.0 \pm 18.4$ & $1.72 \pm 1.40$ \\
\hline Average & $0.77 \pm 0.21$ & $44.3 \pm 18.9$ & $27.4 \pm 18.2$ & $33.4 \pm 22.6$ & $0.51 \pm 0.97$ \\
\hline 1 & $0.90 \pm 0.04$ & $31.4 \pm 5.6$ & $11.4 \pm 7.6$ & $10.0 \pm 7.0$ & $0.01 \pm 0.01$ \\
\hline 2 & $0.95 \pm 0.01$ & $21.3 \pm 2.9$ & $6.1 \pm 4.8$ & $6.2 \pm 5.3$ & $0.01 \pm 0.01$ \\
\hline 3 & $0.94 \pm 0.04$ & $23.9 \pm 6.1$ & $5.3 \pm 4.5$ & $6.2 \pm 4.0$ & $0.10 \pm 0.30$ \\
\hline 4 & $0.88 \pm 0.09$ & $33.7 \pm 10.6$ & $8.8 \pm 3.9$ & $11.4 \pm 10.1$ & $0.83 \pm 1.13$ \\
\hline 5 & $0.91 \pm 0.02$ & $30.1 \pm 3.8$ & $13.1 \pm 8.9$ & $9.6 \pm 6.4$ & $0.01 \pm 0.00$ \\
\hline Average & $0.91 \pm 0.06$ & $28.1 \pm 8.0$ & $8.8 \pm 6.6$ & $8.7 \pm 7.1$ & $0.21 \pm 0.63$ \\
\hline & & & & & \\
\hline
\end{tabular}


It is clearly seen in Tables 4 and Table 5 that the POST setup produced superior results again. Respiratory airflow waveforms are much more accurate, average $\mathrm{R}^{2}$ increased and relative RMSE decreased considerably with both models M1 and M2. In addition to that, tidal volume errors, minute volume errors and BPM errors were smaller. However, when the average POST setup results of Table 4 and Table 5 are compared, it can be seen that models $\mathrm{M} 1$ and M2 with $\mathrm{N}$ value 8 produced both very good results and that there are small differences between the results. However, the PRE setup produced slightly better results with model M1 than with model M2.

\subsection{Accuracy of Airflow Estimates Using Single Respiratory Effort Belt}

To study the effects of individual respiratory effort belts, we also made estimations using only one belt at the time. The use of only one respiratory effort belt simplifies the measurements. In addition, it is less likely that a surgical wound would be in the area of the belt than in the case of two belts, thus allowing for a wider variety of surgical operations.

Table 6 presents the results when the PRE setup and model M4 (linear model with only abdomen belt) were used with $\mathrm{N}$ value 1 and 8 . $\mathrm{N}$ value 1 refers to the conventional linear regression model, where one sample of each predictor variable is used at a time to predict the response variable. It is clearly seen in Table 6 that $\mathrm{N}$ value 8 produced much more accurate waveforms, since average $\mathrm{R}^{2}$ value increased from 0.62 to 0.87 , average relative RMSE decreased from $60.5 \%$ to $34.4 \%$, average BPM error almost halved and average volume errors decreased.

Table 6. Resuls (average value $\pm \mathrm{SD}$ ) for PRE setup and model M4 with $\mathrm{N}$ value 1 (upper results) and $\mathrm{N}$ value 8 (lower results)

\begin{tabular}{l|l|l|l|l|l}
\hline Patient & $\mathrm{R}^{2}$ & $\begin{array}{l}\text { Relative } \\
\text { RMSE [\%] }\end{array}$ & $\begin{array}{l}\text { Abs }\left(\mathrm{V}_{\mathrm{T}}\right. \\
\text { error) [\%] }\end{array}$ & $\begin{array}{l}\text { Abs }\left(\mathrm{V}_{\text {minute }}\right. \\
\text { error) }[\%]\end{array}$ & BPM error \\
\hline 1 & $0.55 \pm 0.08$ & $66.9 \pm 5.7$ & $26.6 \pm 19.5$ & $21.8 \pm 12.4$ & $0.44 \pm 0.51$ \\
\hline 2 & $0.64 \pm 0.05$ & $60.0 \pm 4.5$ & $19.8 \pm 13.6$ & $18.5 \pm 12.5$ & $0.04 \pm 0.05$ \\
\hline 3 & $0.78 \pm 0.09$ & $45.6 \pm 9.8$ & $16.2 \pm 12.0$ & $17.5 \pm 12.3$ & $0.20 \pm 0.39$ \\
\hline 4 & $0.58 \pm 0.10$ & $64.6 \pm 7.0$ & $29.9 \pm 25.7$ & $19.3 \pm 21.7$ & $1.41 \pm 1.15$ \\
\hline 5 & $0.57 \pm 0.06$ & $65.1 \pm 4.8$ & $16.1 \pm 14.0$ & $20.9 \pm 11.4$ & $0.36 \pm 0.48$ \\
\hline Average & $0.62 \pm 0.11$ & $60.5 \pm 10.1$ & $22.3 \pm 18.5$ & $19.6 \pm 14.5$ & $0.51 \pm 0.81$ \\
\hline 1 & $0.87 \pm 0.05$ & $35.5 \pm 7.2$ & $14.9 \pm 11.5$ & $17.9 \pm 9.2$ & $0.03 \pm 0.07$ \\
\hline 2 & $0.95 \pm 0.02$ & $23.0 \pm 3.6$ & $5.4 \pm 5.2$ & $4.8 \pm 5.1$ & $0.01 \pm 0.01$ \\
\hline 3 & $0.88 \pm 0.06$ & $33.5 \pm 9.6$ & $14.5 \pm 12.1$ & $16.5 \pm 12.3$ & $0.09 \pm 0.30$ \\
\hline 4 & $0.83 \pm 0.08$ & $40.7 \pm 9.2$ & $13.4 \pm 9.8$ & $18.0 \pm 11.3$ & $1.05 \pm 1.02$ \\
\hline 5 & $0.84 \pm 0.04$ & $40.3 \pm 4.9$ & $21.1 \pm 9.5$ & $25.0 \pm 8.3$ & $0.01 \pm 0.01$ \\
\hline Average & $0.87 \pm 0.07$ & $34.4 \pm 9.7$ & $13.5 \pm 10.8$ & $16.0 \pm 11.3$ & $0.26 \pm 0.65$ \\
\hline
\end{tabular}

Table 7 presents the results when POST setup and model M4 were used with $\mathrm{N}$ value 1 and 8 . When the average results of Table 6 and Table 7 are compared, it can 
be seen that PRE setup and POST setup with $\mathrm{N}$ value 8 produced both very good results and that there are small differences between the results.

Table 7. Results (average value $\pm \mathrm{SD}$ ) for POST setup and model M4 with $\mathrm{N}$ value 1 (upper results) and $\mathrm{N}$ value 8 (lower results)

\begin{tabular}{l|l|l|l|l|l}
\hline Patient & $\mathrm{R}^{2}$ & $\begin{array}{l}\text { Relative } \\
\text { RMSE [\%] }\end{array}$ & $\begin{array}{l}\text { Abs }\left(\mathrm{V}_{\mathrm{T}}\right. \\
\text { error) [\%] }\end{array}$ & $\begin{array}{l}\text { Abs }\left(\mathrm{V}_{\text {minute }}\right. \\
\text { error) }[\%]\end{array}$ & BPM error \\
\hline 1 & $0.55 \pm 0.06$ & $66.7 \pm 4.2$ & $25.8 \pm 14.9$ & $29.9 \pm 16.6$ & $0.49 \pm 0.54$ \\
\hline 2 & $0.69 \pm 0.06$ & $55.2 \pm 5.7$ & $7.9 \pm 6.4$ & $7.9 \pm 7.2$ & $0.04 \pm 0.06$ \\
\hline 3 & $0.74 \pm 0.08$ & $50.4 \pm 8.2$ & $34.1 \pm 11.1$ & $36.7 \pm 9.3$ & $0.12 \pm 0.29$ \\
\hline 4 & $0.60 \pm 0.07$ & $63.1 \pm 5.6$ & $24.6 \pm 20.4$ & $22.8 \pm 19.2$ & $1.48 \pm 1.12$ \\
\hline 5 & $0.55 \pm 0.04$ & $66.8 \pm 2.9$ & $31.5 \pm 11.3$ & $38.1 \pm 9.0$ & $0.62 \pm 0.61$ \\
\hline Average & $0.63 \pm 0.10$ & $60.3 \pm 8.5$ & $24.2 \pm 16.3$ & $26.2 \pm 17.1$ & $0.57 \pm 0.83$ \\
\hline 1 & $0.86 \pm 0.05$ & $36.3 \pm 6.9$ & $16.2 \pm 11.6$ & $19.0 \pm 9.4$ & $0.03 \pm 0.07$ \\
\hline 2 & $0.94 \pm 0.02$ & $23.8 \pm 3.7$ & $6.9 \pm 6.6$ & $6.1 \pm 6.1$ & $0.01 \pm 0.01$ \\
\hline 3 & $0.89 \pm 0.06$ & $32.8 \pm 9.0$ & $16.4 \pm 12.8$ & $19.1 \pm 12.4$ & $0.10 \pm 0.30$ \\
\hline 4 & $0.79 \pm 0.13$ & $45.3 \pm 12.9$ & $11.3 \pm 6.6$ & $15.3 \pm 13.6$ & $1.23 \pm 1.27$ \\
\hline 5 & $0.87 \pm 0.03$ & $35.8 \pm 4.0$ & $10.6 \pm 8.0$ & $12.8 \pm 7.7$ & $0.13 \pm 0.38$ \\
\hline Average & $0.87 \pm 0.09$ & $35.0 \pm 10.8$ & $12.4 \pm 9.8$ & $14.6 \pm 11.2$ & $0.32 \pm 0.79$ \\
\hline
\end{tabular}

Table 8 presents the results when PRE setup and model M5 (linear model with only rib cage belt) were used with $\mathrm{N}$ value 1 and 8 . However, in some cases the $\mathrm{R}^{2}$ values were negative, because the residual was so large that $\mathrm{R}^{2}$ received negative values. Negative values may occur if the residuals between the spirometer signal and estimated respiratory airflow contain very large values (see section Statistics). This may happen when a regression model fails completely to predict data for example from very different breathing styles. A missing $\mathrm{R}^{2}$ value of a patient means that at least some of the $R^{2}$ values of measurement minutes were negative, thus, the average $R^{2}$ value of a patient could not be computed. Relative RMSE, volume errors and BPM error are clearly worse in this case than in Table 6 and Table 7.

Table 9 presents the results when POST setup and model M5 were used with $\mathrm{N}$ value 1 and 8 . In this setup, $N$ value 1 produced negative $R^{2}$ values for patients 1 and 4 in some measurement minutes, therefore, the average $\mathrm{R}^{2}$ values are missing from them. However, $\mathrm{N}$ value 8 produced much better results, since relative RMSE, volume errors and BPM error decreased considerably. When the average results of Table 8 and Table 9 are compared, a clear difference can be seen between the PRE setup and POST setup. The latter with $\mathrm{N}$ value 8 produced much more accurate waveforms than the other options. Compared to the PRE setup, relative RMSE and volume errors decreased to the fractions.

It is clearly seen from average results in Tables 6-9 that better results were received with the abdominal respiratory effort belt as the $\mathrm{R}^{2}$ values were higher and relative RMSE, volume errors and BPM errors smaller. This might be explained by the fact that during quiet breathing most normal subjects are abdominal breathers when in supine position and thoracic breathers when upright [20]. The better estimates are 
then produced with the dominating abdominal compartment. However, there are differences between the patients. For example, patients 3 and 5 got slightly better results with rib cage respiratory effort belt. A larger data set is clearly needed to confirm the results.

Table 8. Results (average value $\pm \mathrm{SD}$ ) for PRE setup and model M5 with $\mathrm{N}$ value 1 (upper results) and $\mathrm{N}$ value 8 (lower results)

\begin{tabular}{l|l|l|l|l|l}
\hline Patient & $\mathrm{R}^{2}$ & $\begin{array}{l}\text { Relative } \\
\text { RMSE [\%] }\end{array}$ & $\begin{array}{l}\text { Abs }\left(\mathrm{V}_{\mathrm{T}} \text { error) }\right. \\
{[\%]}\end{array}$ & $\begin{array}{l}\text { Abs }\left(\mathrm{V}_{\text {minute }}\right. \\
\text { error) }[\%]\end{array}$ & BPM error \\
\hline 1 & - & $247.9 \pm 86.1$ & $270.0 \pm 129.0$ & $234.0 \pm 113.1$ & $0.30 \pm 0.38$ \\
\hline 2 & - & $180.9 \pm 17.0$ & $177.6 \pm 23.6$ & $175.6 \pm 19.9$ & $0.06 \pm 0.05$ \\
\hline 3 & $0.78 \pm 0.12$ & $45.4 \pm 10.8$ & $14.0 \pm 9.8$ & $16.8 \pm 9.7$ & $0.14 \pm 0.27$ \\
\hline 4 & - & $103.2 \pm 29.3$ & $39.3 \pm 62.3$ & $25.0 \pm 20.6$ & $2.46 \pm 1.87$ \\
\hline 5 & - & $306.3 \pm 52.7$ & $371.5 \pm 107.2$ & $336.9 \pm 101.0$ & $0.46 \pm 0.52$ \\
\hline Average & - & $171.3 \pm 102.7$ & $165.2 \pm 152.5$ & $148.9 \pm 136.0$ & $0.72 \pm 1.31$ \\
\hline 1 & - & $259.6 \pm 92.5$ & $288.0 \pm 142.1$ & $248.3 \pm 122.8$ & $0.23 \pm 0.31$ \\
\hline 2 & - & $131.5 \pm 24.2$ & $127.9 \pm 24.7$ & $125.8 \pm 27.0$ & $0.13 \pm 0.30$ \\
\hline 3 & $0.91 \pm 0.04$ & $29.3 \pm 6.6$ & $13.2 \pm 7.6$ & $15.8 \pm 9.5$ & $0.18 \pm 0.40$ \\
\hline 4 & $0.51 \pm 0.19$ & $68.7 \pm 13.2$ & $31.2 \pm 12.0$ & $27.3 \pm 16.7$ & $2.36 \pm 1.97$ \\
\hline 5 & - & $245.2 \pm 26.7$ & $229.9 \pm 31.9$ & $258.2 \pm 41.6$ & $1.06 \pm 0.94$ \\
\hline Average & - & $143.5 \pm 102.8$ & $135.2 \pm 128.9$ & $130.0 \pm 119.6$ & $0.80 \pm 1.35$ \\
\hline
\end{tabular}

Table 9. Resuls (average value $\pm \mathrm{SD}$ ) for POST setup and model M5 with $\mathrm{N}$ value 1 (upper results) and $\mathrm{N}$ value 8 (lower results)

\begin{tabular}{l|l|l|l|l|l}
\hline Patient & $\mathrm{R}^{2}$ & $\begin{array}{l}\text { Relative } \\
\text { RMSE [\%] }\end{array}$ & $\begin{array}{l}\text { Abs }\left(\mathrm{V}_{\mathrm{T}}\right. \\
\text { error) [\%] }\end{array}$ & $\begin{array}{l}\text { Abs }\left(\mathrm{V}_{\text {minute }}\right. \\
\text { error) [\%] }\end{array}$ & BPM error \\
\hline 1 & - & $73.5 \pm 15.0$ & $36.0 \pm 30.2$ & $28.6 \pm 23.0$ & $0.37 \pm 0.48$ \\
\hline 2 & $0.61 \pm 0.06$ & $62.4 \pm 4.6$ & $21.1 \pm 7.7$ & $22.0 \pm 6.4$ & $0.06 \pm 0.05$ \\
\hline 3 & $0.74 \pm 0.18$ & $48.8 \pm 15.2$ & $13.5 \pm 8.8$ & $10.0 \pm 10.0$ & $0.15 \pm 0.28$ \\
\hline 4 & - & $83.3 \pm 13.3$ & $44.6 \pm 25.0$ & $53.8 \pm 19.0$ & $2.37 \pm 2.23$ \\
\hline 5 & $0.55 \pm 0.03$ & $66.8 \pm 2.1$ & $27.1 \pm 14.5$ & $35.3 \pm 10.1$ & $0.75 \pm 0.61$ \\
\hline Average & - & $67.6 \pm 16.5$ & $29.1 \pm 22.5$ & $30.2 \pm 21.3$ & $0.74 \pm 1.36$ \\
\hline 1 & $0.78 \pm 0.15$ & $45.0 \pm 14.9$ & $17.2 \pm 13.0$ & $15.9 \pm 15.3$ & $0.37 \pm 0.53$ \\
\hline 2 & $0.86 \pm 0.03$ & $37.8 \pm 4.0$ & $17.6 \pm 9.6$ & $14.7 \pm 9.3$ & $0.02 \pm 0.01$ \\
\hline 3 & $0.89 \pm 0.09$ & $31.0 \pm 10.5$ & $11.2 \pm 9.2$ & $9.7 \pm 8.1$ & $0.11 \pm 0.30$ \\
\hline 4 & $0.52 \pm 0.16$ & $68.8 \pm 11.2$ & $37.4 \pm 10.6$ & $34.9 \pm 18.3$ & $1.76 \pm 1.76$ \\
\hline 5 & $0.90 \pm 0.03$ & $31.4 \pm 5.1$ & $9.3 \pm 9.4$ & $12.2 \pm 7.4$ & $0.23 \pm 0.47$ \\
\hline Average & $0.78 \pm 0.18$ & $44.1 \pm 17.5$ & $19.5 \pm 14.4$ & $18.1 \pm 15.6$ & $0.54 \pm 1.10$ \\
\hline
\end{tabular}

As expected, the results with one respiratory effort belt were worse than with two belts, but not very much. If we compare the results of POST setup with $\mathrm{N}$ value 8 from Table 7 (abdominal belt, model M4) and Table 4 (two belts, model M1), it is seen that $\mathrm{R}^{2}$ increased from 0.87 to 0.91 , relative RMSE decreased from $35.0 \%$ to 
$28.1 \%$, tidal volume error decreased from $12.4 \%$ to $8.4 \%$, minute volume error decreased from $14.6 \%$ to $8.6 \%$ and BPM error decreased from 0.32 to 0.23 . Conventionally, it is expected that two compartments (rib cage and abdominal) are needed for the estimation of the airflow [21]. With this measurement data, for some patients, the results with one belt were almost as good as with two belts. A possible reason for that could be that the patients were in supine position during the whole measurement sessions and they did not move very much. Caused by this, model training data was quite similar to testing data and the resulting estimated airflow was accurate.

\subsection{Case Study 1: Performance Difference Between Setups}

Fig. 2 demonstrates the performance difference between PRE and POST setups. In this case, model M1 (two respiratory effort belts, $\mathrm{N}=16$ ) was used firstly with the PRE setup and secondly with the POST setup. The measurement data was from patient 2. It can be seen from Fig. 2 that there were clear differences with the estimated respiratory airflows (PRE setup with dotted line and POST setup with bold line). Following numerical results demonstrate these differences further. The results for the whole measurement minute with PRE setup were: $\mathrm{R}^{2}$ was 0.88 , relative RMSE 35.0 $\%$, tidal volume error $27.4 \%$, minute volume error $26.2 \%$ and BPM error 0.04 . Equivalently results for the POST setup were: $\mathrm{R}^{2}$ was 0.94 , relative RMSE $24.8 \%$, tidal volume error $1.9 \%$, minute volume error $0.6 \%$ and BPM error 0.04. Although, the PRE setup was otherwise remarkably worse than POST setup in this case, BPM was estimated very accurately.

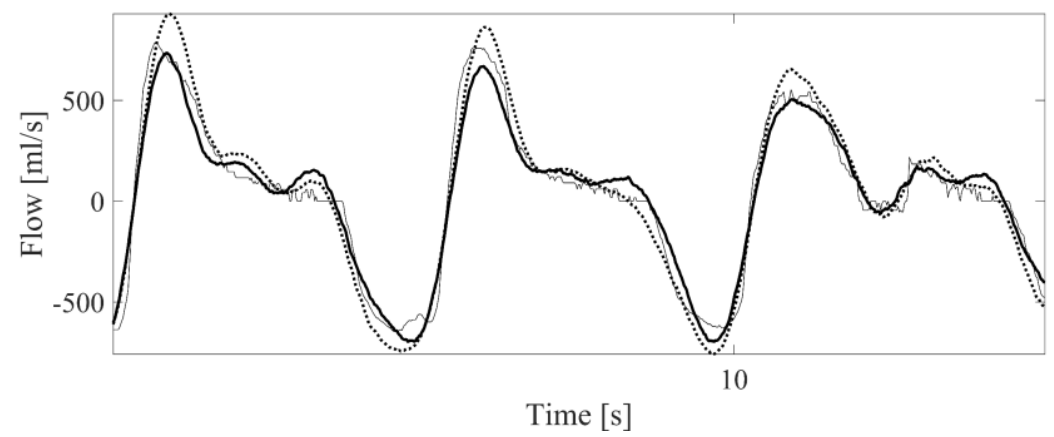

Fig. 2. Short segments of example signals depicting the difference of PRE and POST setups: spirometer signal (thin line), the first estimated respiratory airflow signal (two belts, PRE setup, model $\mathrm{M} 1, \mathrm{~N}=16$, dotted line) and the second estimated respiratory airflow (two belts, POST setup, model $\mathrm{M} 1, \mathrm{~N}=16$, bold line).

\subsection{Case Study 2: Performance Differences Between Models}

Fig. 3 demonstrates the performance difference between models M1 and M2. In this case, POST setup (two respiratory effort belts, $\mathrm{N}=8$ ) was used with model M1 and secondly with model M2. The measurement data was from patient 1 . It can be seen 
from Fig. 3 that there were very small differences with the estimated respiratory airflows (M1 with dotted line and M2 with bold line). Both models produced excellent estimates of airflow. Following numerical results demonstrate this further. The results for the whole measurement minute with model M1 were: $\mathrm{R}^{2}$ was 0.95 , relative RMSE $21.6 \%$, tidal volume error $-1.9 \%$, minute volume error $-2.2 \%$ and BPM error 0.11 . Equivalently results for the model $\mathrm{M} 2$ were: $\mathrm{R}^{2}$ was 0.95 , relative RMSE 23.3 $\%$, tidal volume error $-6.0 \%$, minute volume error $5.3 \%$ and BPM error 0.15 .

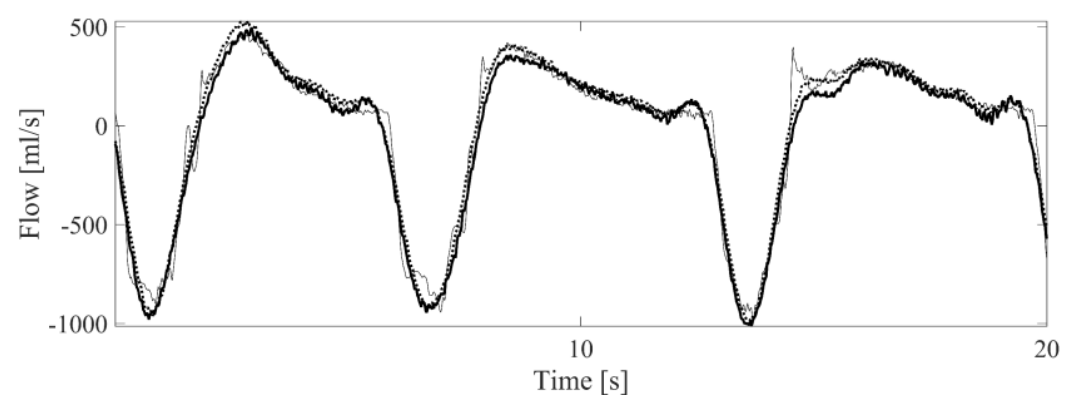

Fig. 3. Short segments of example signals depicting slight differences between model M1 and model M2: spirometer signal (thin line), the first estimated respiratory airflow signal (two belts, POST setup, model M1, N = 8, dotted line) and the second estimated respiratory airflow (two belts, POST setup, model $\mathrm{M} 2, \mathrm{~N}=8$, bold line).

Fig. 4 demonstrates the performance difference between models M1 (both respiratory effort belts), M4 (only abdominal belt) and M5 (only rib cage belt). In these cases, POST setup with $\mathrm{N}$ value 8 was used. The measurement data was from patient 1 . It can be seen from Fig. 4 that model M1 produced clearly the best results. Following numerical results demonstrate the differences between models. The results for the whole measurement minute with model M1 were: $\mathrm{R}^{2}$ was 0.93 , relative RMSE 26.1 $\%$, tidal volume error $-5.4 \%$, minute volume error $-5.8 \%$ and BPM error 0.18 . Results for the model M4 were: $\mathrm{R}^{2}$ was 0.92 , relative RMSE $28.6 \%$, tidal volume error $17.2 \%$, minute volume error $-15.0 \%$ and BPM error 0.00 . Results for the model M5, which was clearly the worst in this case, were: $\mathrm{R}^{2}$ was 0.86 , relative RMSE $38.0 \%$, tidal volume error $3.2 \%$, minute volume error $20.9 \%$ and BPM error 0.59 .

\subsection{Case Study 3: Low Airflow}

Patients are often weak and tired after the surgery so their respiration contains very low airflows. It is important to estimate these parts accurately so that they are not interpreted as no-airflow parts and no false alarms are created. Fig. 5 depicts short segments of example signals with low airflow. Estimation model M1 $(\mathrm{N}=16)$ was used with the POST setup for the measurement signals of patient 3 . Results for the whole measurement minute were: $\mathrm{R}^{2}$ was 0.93 , relative RMSE $25.8 \%$, tidal volume error $0.0 \%$, minute volume error $-10.5 \%$ and BPM error -0.01 . It can be seen from Fig. 5 that the spirometer signal is estimated with good accuracy. 


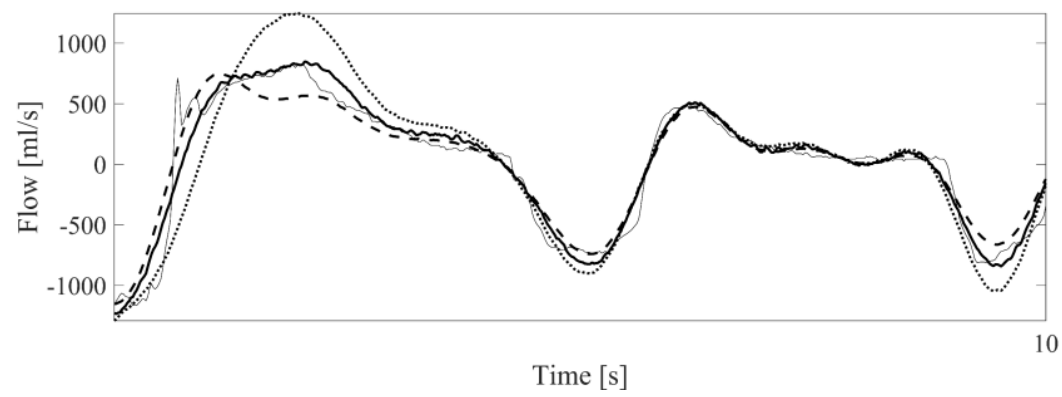

Fig. 4. Short segments of example signals depicting differences between models M1, M4 and M5: spirometer signal (thin line), the first estimated respiratory airflow signal (two belts, POST setup, model $\mathrm{M} 1, \mathrm{~N}=8$, bold line), the second estimated respiratory airflow (abdominal belt, POST setup, model M4, $\mathrm{N}=8$, dashed line) and the third estimated respiratory airflow (rib cage belt, POST setup, model M5, $\mathrm{N}=8$, dotted line).

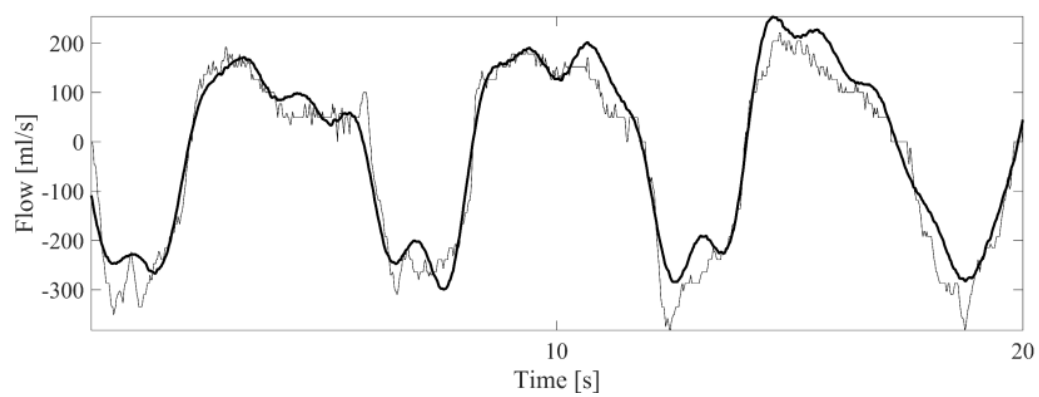

Fig. 5. Short segments of example signals with low airflow: spirometer signal (thin line) and the estimated respiratory airflow signal (POST setup, model M1, $\mathrm{N}=16$, bold line)

\subsection{Case Study 4: Thoracoabdominal Asynchrony}

Thoracoabdominal asynchrony refers to the non-coincident motion of rib cage and abdomen and is characterized by a time lag between motion of rib cage and abdomen. It is often observed in many respiratory disorders and/or respiratory muscle dysfunctions. Clinically, it is assessed as a sign of respiratory distress and increased work of breathing. Measurement data of patient 4 included thoracoabdominal asynchrony more or less during the whole measurement session. Fig. 6 depicts one example of thoracoabdominal asynchrony. Estimation model M1 $(\mathrm{N}=8)$ was used with the POST setup and the results were the following: $\mathrm{R}^{2}$ was 0.94 , relative RMSE $24.2 \%$, tidal volume error $1.8 \%$, minute volume error $-3.1 \%$ and BPM error 0.19 . These results are consistent with our earlier findings indicating that our method produces very good results with thoracoabdominal asynchrony signals as well [18]. 

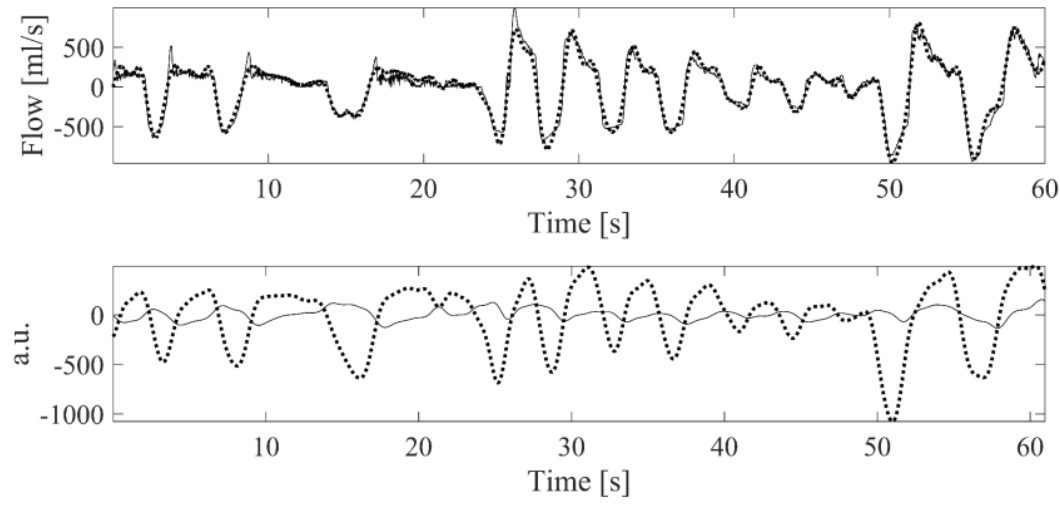

Fig. 6. Example signals of thoracoabdominal asynchrony. Upper subfigure: spirometer signal (solid line) and the estimated respiratory airflow signal (POST setup, model M1, N = 8, dotted line). Lower subfigure: rib cage respiratory effort belt signal (solid line) and abdominal respiratory effort belt signal (dotted line).

Fig. 7 demonstrates the performance difference of models M4 and M5. The same measurement minute from patient 4 as in the previous case was used in these cases as well. Firstly, model M4 $(\mathrm{N}=8)$ and POST setup were used (upper subfigure) and secondly, model M5 ( $=8)$ and POST setup were used (lower subfigure). It can be seen from subfigures that there were clear differences with the estimated respiratory airflows and model M4 produced better estimates. Numerical results for model M4 were: $\mathrm{R}^{2}$ was 0.81 , relative RMSE $43.0 \%$, tidal volume error $14.7 \%$, minute volume error $21.5 \%$ and BPM error 1.25. Equivalently results for model M5 were: $\mathrm{R}^{2}$ was 0.35 , relative RMSE $80.7 \%$, tidal volume error $-28.9 \%$, minute volume error -25.7 $\%$ and BPM error 2.00 .

It can be seen from Fig. 6 and Fig. 7 that if respiratory airflow signal is estimated by using both respiratory effort belts, the resulting waveforms are much more accurate: $\mathrm{R}^{2}$ value 0.94 (relative RMSE $24.2 \%$ ) compared to $0.81(43.0 \%)$ and $0.35(80.7$ $\%$ ) of models M4 and M5, respectively. In addition to that, volume errors and BMP error are only fractions when model M1 is used.

\subsection{Case Study 5: Hypopneic Event}

A hypopneic event is commonly defined as greater than $30 \%$ reduction in airflow for 10 seconds or longer. Fig. 8 depicts one hypopneic event of patient 4 with COPD. Here, model M1 $(\mathrm{N}=8)$ was used with the POST setup. In this case, $\mathrm{R}^{2}$ was 0.80 , relative RMSE $44.4 \%$, tidal volume error $5.1 \%$, minute volume error $1.4 \%$ and BMP error 1.08. It can be seen that the method was able to estimate respiratory airflow very well even in a complicated situation like this.

Fig. 9 demonstrates the performance of models M4 and M5 during the same hypopneic event as in the previous case. Firstly, the model M4 $(\mathrm{N}=8)$ and POST setup 
was used (upper subfigure) and secondly, the model M5 $(\mathrm{N}=8)$ and POST setup was used (lower subfigure). Numerical results for the model M4 were: $\mathrm{R}^{2}$ was 0.60 , relative RMSE $63.3 \%$, tidal volume error $15.9 \%$, minute volume error $23.1 \%$ and BPM error 1.08. Similarly, results for model M5 were: $\mathrm{R}^{2}$ was 0.44 , relative RMSE $74.9 \%$, tidal volume error $-32.0 \%$, minute volume error $-38.4 \%$ and BPM error 2.24. Model M1 produced again the best results. However, model M4 estimated BPM as accurately as model M1 in this case.
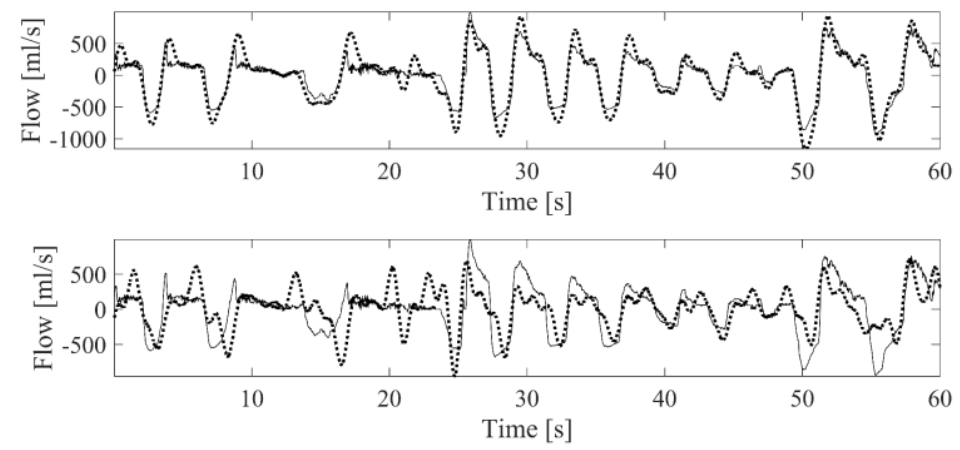

Fig. 7. Segments of example signals depicting the difference of models M4 and M5. Upper subfigure: spirometer signal (solid line) and the estimated respiratory airflow signal (POST setup, model M4, $\mathrm{N}=8$, dotted line). Lower subfigure: spirometer signal (solid line) and the estimated respiratory airflow signal (POST setup, model M5, $\mathrm{N}=8$, dotted line).
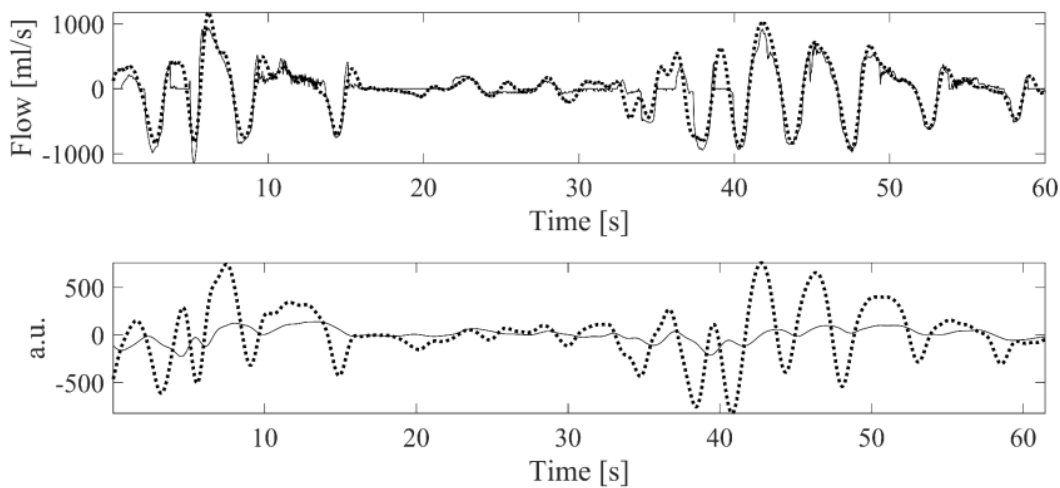

Fig. 8. Example signals of hypopneic event. Upper subfigure: spirometer signal (solid line) and the estimated respiratory airflow signal (POST setup, model $\mathrm{M} 1, \mathrm{~N}=8$, dotted line). Lower subfigure: rib cage respiratory effort belt signal (solid line) and abdominal respiratory effort belt signal (dotted line). 

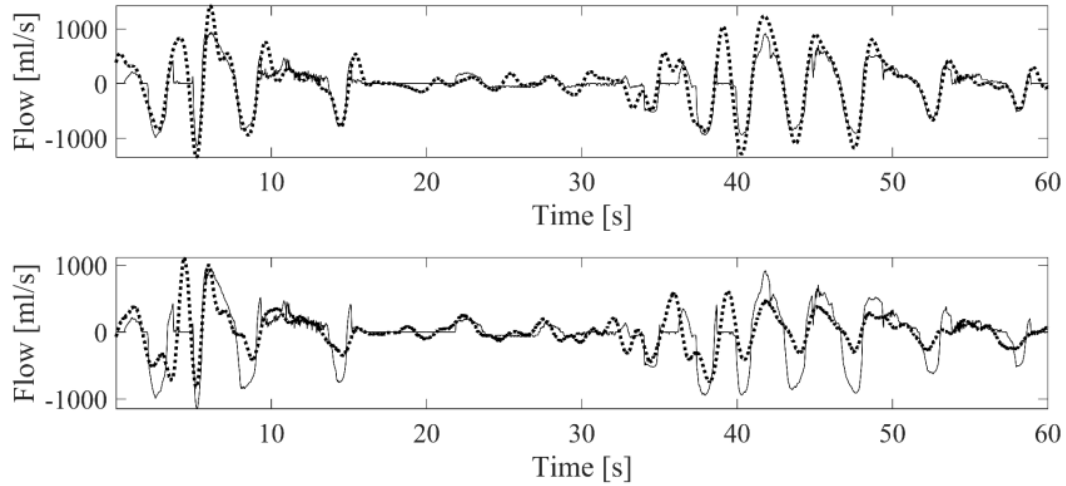

Fig. 9. Segments of example signals during hypopneic event depicting the difference of models M4 and M5. Upper subfigure: spirometer signal (solid line) and the estimated respiratory airflow signal (POST setup, model M4, $\mathrm{N}=8$, dotted line). Lower subfigure: spirometer signal (solid line) and the estimated respiratory airflow signal (POST setup, model M5, $\mathrm{N}=8$, dotted line).

\subsection{Case Study 6: Apneic Event}

An apneic event is usually defined as no detected breaths for periods of longer than 10 seconds. Fig. 10 depicts an example of apneic event from measurement data of patient 5. An apneic event can be seen in the signals from $35 \mathrm{sec}$ to $49 \mathrm{sec}$. In this case, model M1 $(\mathrm{N}=8)$ was used with the POST setup. During an apneic event, the rib cage ceases to move, but the abdomen is moving. There is no air exchange, so there is no airflow signal either. It can be seen from Fig. 10 that during the obstruction airflow was zero, but because there was a movement in respiratory effort belts (especially in the abdominal belt), the estimated respiratory airflow signal also showed activity. The same phenomenon was also encountered by Drummond et al. [13] and Voscopoulos et al. [22].

Fig. 11 demonstrates the performance of models M4 and M5 during the same apneic event as in the previous case. Firstly, the model M4 $(\mathrm{N}=8)$ and POST setup was used (upper subfigure) and secondly, the model M5 $(\mathrm{N}=8)$ and POST setup was used (lower subfigure). It can be seen from the lower subfigure of Fig. 11 that during the apneic event model M5, which uses only rib cage effort belt produced better estimates.

\subsection{Limitations of Study}

The study had a number of limitations. Firstly, the study included only five patients. The study should be repeated with a larger data set in order to draw more general conclusions. Secondly, respiratory effort belts cannot be used at all if the surgical wound is in the area where the belts are placed. However, the proposed method could be applied to the measurement data acquired with other sensors without this kind of 
restriction, such as acceleration sensors. Thirdly, as was pointed out in Section 3.2, during the apneic event there is no respiratory airflow but still the estimated respiratory airflow exists due to abdominal movements.
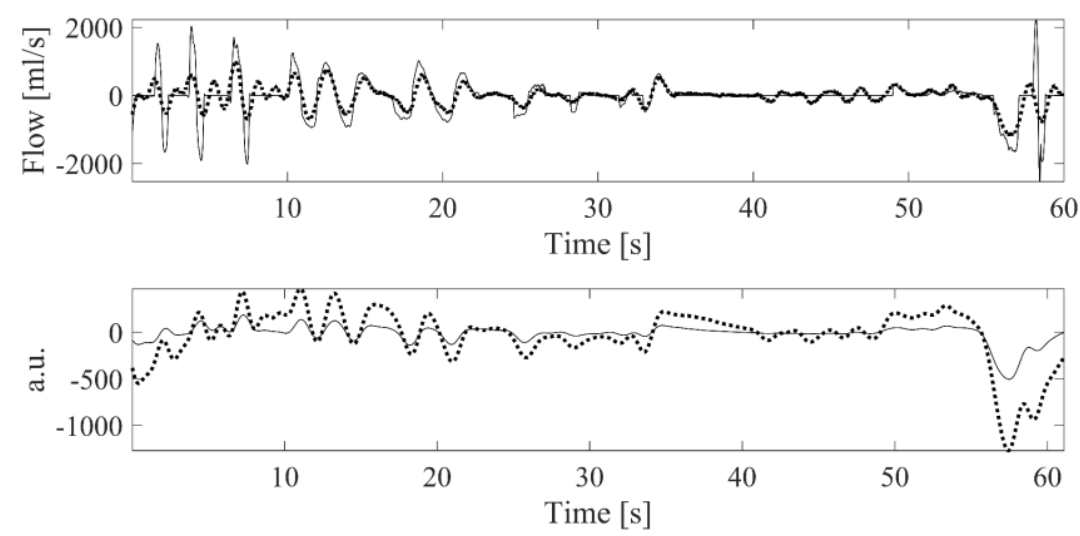

Fig. 10. Short segments of example signals during apneic event. Upper subfigure: spirometer signal (solid line) and the estimated respiratory airflow signal (POST setup, model M1, N=8, dotted line). Lower subfigure: rib cage respiratory effort belt signal (solid line) and abdominal respiratory effort belt signal (dotted line).
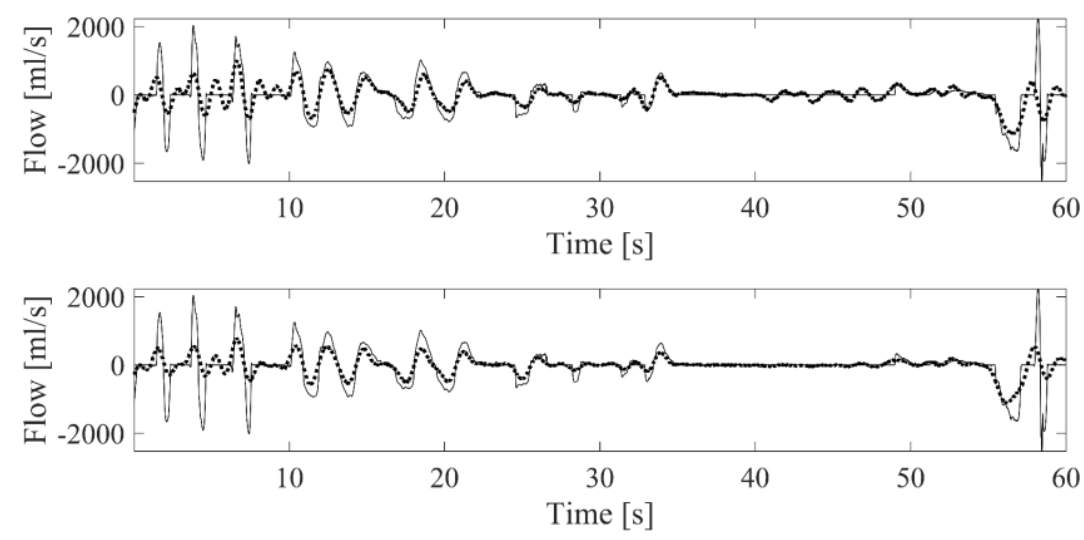

Fig. 11. Segments of example signals during apneic event depicting the difference of models M4 and M5. Upper subfigure: spirometer signal (solid line) and the estimated respiratory airflow signal (POST setup, model M4, $\mathrm{N}=8$, dotted line). Lower subfigure: spirometer signal (solid line) and the estimated respiratory airflow signal (POST setup, model M5, $\mathrm{N}=8$, dotted line). 


\section{Conclusions}

A novel method was proposed for accurate estimation of continuous respiratory airflow postoperatively. The data from respiratory effort belts were calibrated with a spirometer using an extended multiple linear regression method. Several models for calibration were compared experimentally. The use of two respiratory effort belts was studied in detail and compared with a single belt approach. It was studied whether calibration models should be trained with preoperative data or postoperative data to improve performance. The results showed that training the estimation models with the postoperative data produced much more accurate results than training the estimation model with the preoperative data.

It was demonstrated with data from five patients in a postoperative situation that estimated respiratory airflow signals have accurate waveforms, tidal volume, minute volume and respiratory rate. The method produced good estimates even from challenging respiration signals: low airflows, hypopneic events and thoracoabdominal asynchrony. It was also shown that a single belt measurement, especially the abdominal belt, can be sufficient in some cases. The use of only one respiratory effort belt simplifies the measurements. In addition, it is less likely that a surgical wound would be in the area of the belt than in the case of two belts, thus allowing for a wider variety of surgical operations. However, the study should be repeated with a larger data set in order to confirm the results and in order to draw more general conclusions.

This kind of continuous and real-time respiratory monitoring could provide potential for optimizing pain management and enable timely interventions with a decreased risk of postoperative respiratory complications. For patients at risk for respiratory depression, personalized and more optimal opioid dosing is possible. In addition, for patients with adequate respiratory function, more aggressive and effective dosing could be provided when necessary. All this in its part leads to improved patient safety and satisfaction. Additionally, complications from inadequate pain control are reduced and as a consequence of that health care costs are decreased.

In summary, the proposed method is able to produce estimates of respiratory airflow waveforms to enable accurate, real-time, continuous, and non-invasive respiratory monitoring postoperatively.

Acknowledgements. Finnish Cultural Foundation, North Ostrobothnia Regional Fund and International Doctoral Programme in Biomedical Engineering and Medical Physics (iBioMEP) are gratefully acknowledged for financial support.

\section{References}

1. Cepeda, M.S., Farrar, J.T., Baumgarten, M., Boston, R., Carr, D.B., Strom, B.L.: Side effects of opioids during short-term administration: Effect of age, gender, and race. Clin. Pharmacol. Ther. 74(2), 102-112 (2003)

2. Etches, R.: Respiratory depression associated with patient-controlled analgesia: a review of eight cases. Can. J. Anaesth. 41(2), 125-132 (1994) 
3. Gamil, M., Fanning, A.: The first 24 hours after surgery. A study of complications after 2153 consecutive operations. Anaesthesia 46, $712-715$ (1991)

4. Taylor, S., Kirton, O.C., Staff, I, Kozol, R.A.: Postroperative day one: a high risk period for respiratory events. Am. J. Surg. 190(5), 752-756 (2005)

5. Ramsay, M.A.E., Usman, M., Lagow, E., Mendoza, M., Untalan, E., De Vol, E.: The accuracy, precision and reliability of measuring ventilatory rate and detecting ventilatory pause by rainbow acoustic monitoring and capnometry. Anesth. Analg. 117(1), 69-75 (2013)

6. Mailey, J., Digiovine, B., Baillod, D., Gnam G., Jordan, J., Rubinfeld, I.: Reducing hospital standardized mortality rate with early interventions. J. Trauma Nurs. 13(4), 178-182 (2006)

7. Schein, R.M.H., Hazday, N., Pena, M., Ruben, B.H., Sprung, C.L.: Clinical antecedents to in-hospital cardiopulmonary arrest. Chest 98(6), 1388-1392 (1990)

8. George, J.A., Lin, E.E., Hanna, M.N., Murphy, J.D., Kumar, K., Ko, P.S., Wu, C.L.: The effect of intravenous opioid patient-controlled analgesia with and without background infusion on respiratory depression: a meta-analysis. J. Opioid Manag. 6(1), 47-54 (2010)

9. Lynn, L.A., Curry, J.P.: Patterns of unexpected in-hospital deaths: a root cause analysis. Patient Saf. Surg. 5:3 (2011)

10. Paine, C.W., Goel, V.V., Ely, E., Stave, C.D. Stemler, S., Zander M., Bonafide C.P.: Systematic review of physiologic monitor alarm characteristics and pragmatic interventions to reduce alarm frequency. J. Hosp. Med. 11(2), 136-144 (2016)

11. Wiklund, L., Hök, B., Ståhl K., Jordeby-Jönsson, A.: Postanesthesia monitoring revisited: Frequency of true and false alarms from different monitoring devices. J. Clin. Anesth. 6(3), 182-188 (1994)

12. Lovett, P.B., Buchwald, J.M., Sturmann, K., Bijur, P.: The vexatious vital: neither clinical measurements by nurses nor an electronic monitor provides accurate measurements of respiratory rate in triage. Ann. Emerg. Med. 45(1), 68-76 (2005)

13. Drummond, G.B., Bates, A., Mann, J., Arvind, D.K.: Characterization of breathing patterns during patient-controlled opioid analgesia. Br. J. Anaesth. 111(6), 971-978 (2013)

14. Voscopoulos, C.J., MacNabb, C.M., Brayanov, J., Qin, L., Freeman, J., Mullen, G.J., Ladd, D., George, E.: The evaluation of a non-invasive respiratory volume monitor in surgical patients undergoing elective surgery with general anesthesia. J. Clin. Monit. Comput. 29(2), 223-230 (2015)

15. Voscopoulos, C., Ladd, D., Campana, L., George, E.: Non-invasive respiratory volume monitoring to detect apnea in post-operative patients: case series. J. Clin. Med. Res. 6(3), 209-214 (2014)

16. Voscopoulos, C.J., MacNabb, C.M., Freeman, J., Galvagno, S.M., Ladd, D., George, E.: Continuous noninvasive respiratory volume monitoring for the identification of patients at risk for opioid-induced respiratory depression and obstructive breathing patterns. J. Trauma Acute Care Surg. 77(3), S208-S215 (2014)

17. Masa, J.F., Corral, J., Martin, M.J., Riesco, J.A., Sojo, A., Hernández, M., Douglas, N.J.: Assessment of thoracoabdominal bands to detect respiratory effort-related arousal. Eur. Respir. J. 22, 661-667 (2003)

18. Seppänen, T.M., Alho, O.-P., Seppänen, T.: Reducing the airflow waveform distortions from breathing style and body position with improved calibration of respiratory effort belts. Biomed. Eng. Online 12:97 (2013)

19. Montgomery, D.C., Peck, E.A., Vining, G.G.: Introduction to Linear Regression Analysis. $3^{\text {rd }}$ edition. Wiley, New York (2001)

20. Verschakelen, J.A., Demedts, M.G.: Normal thoracoabdominal motions. Influence of sex, age, posture, and breath size. Am. J. Respir. Crit. Care Med. 151(2), 399-405 (1995) 
21. Konno, K., Mead, J.: Measurement of separate volume changes of rib cage and abdomen during breathing. J. Appl. Physiol. 22(3), 407-422 (1967)

22. Voscopoulos, C, Brayanov, J., Ladd, D., Lalli, M., Panasyuk, A., Freeman, J.: Evaluation of a novel noninvasive respiration monitor providing continuous measurement of minute ventilation in ambulatory subjects in a variety of clinical scenarios. Anesth. Analg. 117(1), 91-100 (2013) 